\title{
Investigation of the Effect of the Addition of Petroleum Waste to Interlocking Bricks Constituent
}

\author{
P. O. Atanda ${ }^{1}$, O. O. Oluwole ${ }^{2 *}$ and I. D. Olumor ${ }^{1}$ \\ ${ }^{1}$ Department of Materials Science and Engineering O.A.U., Ile-Ife, Nigeria. \\ ${ }^{2 *}$ Mechanical Engineering Department, University of Ibadan. \\ Corresponding Author: oluwoleo2@asme.org
}

\begin{abstract}
Incinerator ash was investigated for its potential use as a replacement for sand and cement in concrete interlocking bricks. The physical characteristics of the raw materials were examined. Two sets of mixes were prepared. For the first set, sand and water quantities were fixed while incinerator ash was used at $0 \%$ to $100 \%$ replacement by weight for cement in steps of $10 \%$. In the second set, incinerator ash was used at $0 \%$ to $100 \%$ replacement by weight for sand while cement and water quantities was fixed. The mixing proportions for cement, sand and water were 1:3:0.7, respectively. Compressive strength and leachability tests were performed on the specimens.

Results showed that the replacement of sand by incinerator ash up to $40 \%$ exhibited higher compressive strength than the control mix (0\% incinerator ash) after 28 days curing. Maximum compressive strength of $33.33 \mathrm{~N} / \mathrm{mm}^{2}$ was obtained after 28 days curing using using $20 \%$ incinerator ash substitution for sand. Replacement of cement by incinerator ash up to $20 \%$ exhibited higher compressive strength than the control mix. Compressive strength of $28.2 \mathrm{~N} / \mathrm{mm}^{2}$ was achieved after 28 days curing period using a 20\% ash substitution for cement. Leaching of heavy metals ( $\mathrm{Pb}$ and $\mathrm{Cd}$ ) present in the ash was observed in concentrated nitric acid.
\end{abstract}

Key words: interlocking bricks; sand; cement; replacement; petroleum waste ash; compressive strength

\section{INTRODUCTION}

Interlocking bricks are a form of concrete for pavements and roads arranged to interlock with each other so as to reinforce each other and overcome buckling. They have special 
composition that allows for stress resistance without necessarily having to be reinforced with metal rods as is the case for concrete beams. Concrete generally is a construction material composed of cement as well as other materials such as sand, water, aggregates and chemical admixture s[1]. The word concrete comes from the Latin word "concretus", which means "hardened" or "hard” [2]. Interlocking bricks are engineering materials designed to withstand compressive loads.

Investigation of the effect of the addition of petroleum waste ash to interlocking bricks constituent is a project that aims at investigating the possibility of reducing or even replacing the cement content of interlocking bricks with waste ash, while the interlocking brick still maintains desired compressive strength.

Fly-ash, the most commonly used incinerator ash product- is a remarkable material that cost effectively improves the performance of products it is added to. For instance, in making concrete, cement mixed with water served as the glue which holds strong aggregates together. Fly ash works intandem with cement in the production of concrete materials. Concrete containing fly ash is easier to work because the tiny, glassy beads create a lubricating effect that causes concrete to flow and pump better, to fill forms more completely and to do it all using up to 10 percent less water [3].

Because the tiny fly ash particles fill the microscopic spaces in the concrete, and because less water is required, concrete using fly ash is denser and more durable. Fly ash reacts chemically with lime that is given off by cement hydration, creating more of the glue that holds concrete together. That makes concrete containing fly ash stronger over time than concrete made only with cement. According to [4], fly ash is comprised of non-combustible mineral portion of waste petroleum consumed in a petroleum waste incinerator. Fly ash particles are glassy, spherical shaped ball bearings- typically finer than cement particles- that are collected from the combustion air stream exiting the plant. There are two basic types of fly ash: class F and class C [5]. Both types react in concrete in similar ways. Both undergo a pozzolanic reaction with lime from cement hydration.

The main benefit of fly ash in concrete is that it not only reduces the amount of non durable calcium oxide (lime), but in the process converts it into calcium silicate hydrate (CSH), which is the strongest and most durable portion of the paste in concrete. To fully appreciate the benefits of fly ash in concrete, the basics of producing exceptional concrete must be understood. Concrete is a composite material which essentially consists of two components: aggregates and cementiceous paste. To produce good concrete, it is extremely important to have a smooth gradation of materials from rocks down to the finest particles. In other words, there must be a good mix of particle sizes so that the smaller rock and sand fill the voids left between the larger particles [1]. There is a general misconception of durability and strength when talking about concrete. Durability is the ability to maintain integrity and strength over time. Strength is only a measure of the ability to sustain loads at a given point in time [6]. Cement normally gains most of its strength within 28 days, thus the reasoning behind specification normally requiring determination of 28 days strength as standard. As lime from 
cement hydration becomes available, it reacts with fly ash. Typically, concrete made from fly ash will be slightly lower in strength than straight cement concrete up to 28 days, equal strength at 28 days and substantially higher strength within a year. Conversely, in straight cement concrete, lime remains intact and over time is susceptible to effects of weathering resulting in loss of strength and durability [7].

\section{METHODOLOGY}

\subsection{Sample preparation}

The test specimens were prepared as $2 \mathrm{~cm}$ diameter by $4 \mathrm{~cm}$ length cylinders. Moulds for the cylindrical specimens were made of rigidly constructed non-absorbent plastic tubes to facilitate removal of the moulded specimen without damage (Fig.1).

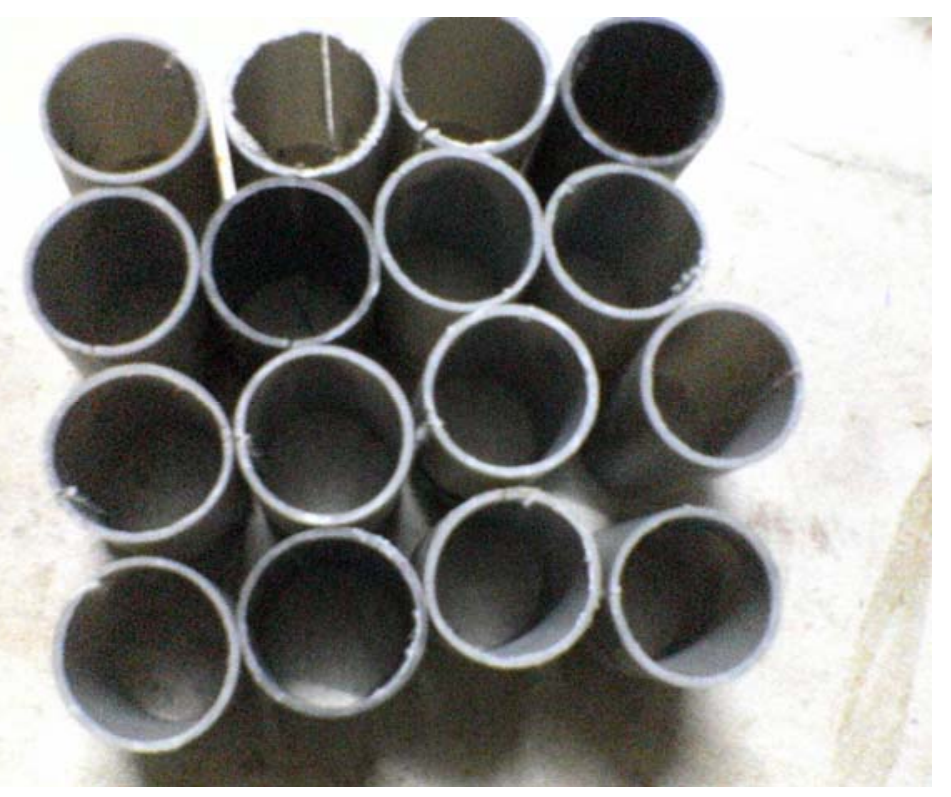

Fig.1: Plastic moulds

The sand used was thoroughly washed and dried sieved. Sand used for ramming were not more than $1.4 \mathrm{~mm}$ size after sieving. Distilled water was used for mixing and curing of the concrete specimens.

The ash used was obtained from Delta Environmental Logistics, Port-Harcourt, Nigeria (Fig.2). The ash sample was ground in a ceramic mortar and sieved. $125 \mu \mathrm{m}$ size of ash was used for the experiment folowing BS 410 full tolerance test sieve. 


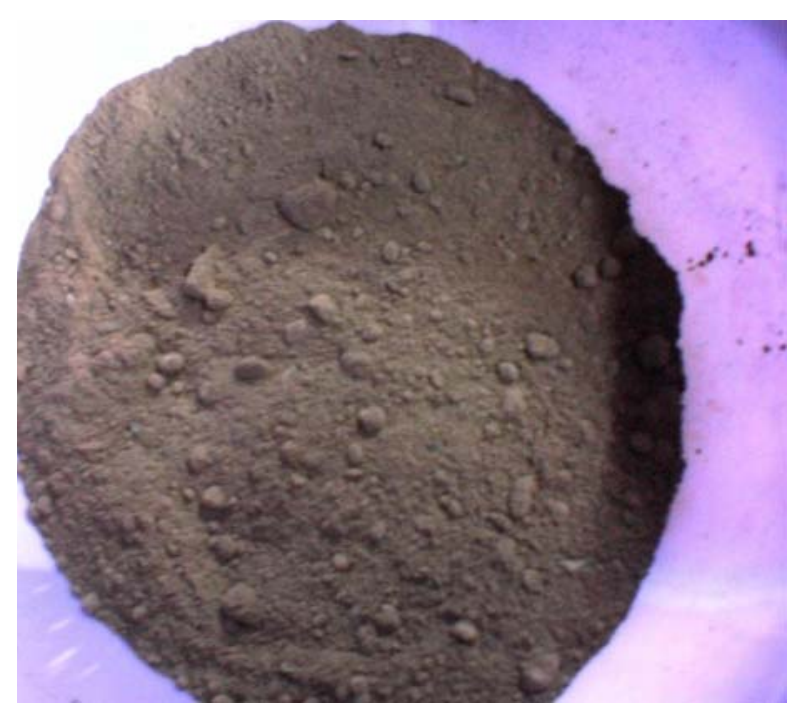

Fig.2: Unsieved ash

In the first set of samples, percentage of sand and water in the mixes were kept constant while cement content was reduced in steps of $10 \%$ and supplementing the cement reduction with with ash additive to the same tone of reduction (Table 1).

Table 1: Proportioning mix for samples with Ash used as substitute for Cement.

\begin{tabular}{|l|c|c|c|}
\hline $\begin{array}{l}\text { Specimen } \\
\text { identification }\end{array}$ & \%wt of ash & $\begin{array}{l}\text { Weight of cement } \\
\text { (g) }\end{array}$ & Weight of Ash (g) \\
\hline C1 & 10 & 6.705 & 0.745 \\
C2 & 20 & 5.960 & 1.490 \\
C3 & 5.215 & 2.235 \\
C4 & 40 & 4.470 & 2.980 \\
C5 & 50 & 3.725 & 3.725 \\
C6 & 60 & 2.980 & 4.470 \\
C7 & 70 & 2.235 & 5.215 \\
C8 & 80 & 1.490 & 5.960 \\
C9 & 90 & 0.745 & 6.705 \\
C10 & 100 & 0 & 7.450 \\
\hline
\end{tabular}

A second set was prepared with water and cement contents kept constant while sand content was reduced from in steps of $10 \%$ and replaced with ash.(Table 2). A mixture of sand, cement and water in the proportion 3:1:0.7 were prepared. Control sample had a mix proportion of of $22.340 \mathrm{~g}$ of sand, $5.210 \mathrm{~g}$ of water and $7.450 \mathrm{~g}$ of Portland cement.

\subsection{Moulding Specimens}

During the assembly of the plastic moulds, the joints and bottom of the moulds were covered with a thin film of petroleum jelly and wrapped with polyethene in order to ensure that no water escaped during ramming and setting. The assembled moulds were then placed on a flat 
surface and held firmly. Immediately after mixing, the whole of the mortar were placed in the mould cavity and then subsequently compacted and rammed for about 2 minutes.

Table 2: Proportioning mix for samples with Ash used as substitute for Sand.

\begin{tabular}{|c|c|c|c|}
\hline $\begin{array}{l}\text { Sample } \\
\text { identification }\end{array}$ & $\begin{array}{c}\text { \%eight of sand } \\
\text { (g) }\end{array}$ & $\begin{array}{c}\text { Weight of ash } \\
\text { (g) }\end{array}$ \\
\hline S1 & 10 & 20.106 & 2.234 \\
S2 & 20 & 17.872 & 4.468 \\
S3 & 30 & 15.638 & 6.702 \\
S4 & 40 & 13.404 & 8.936 \\
S5 & 50 & 11.170 & 11.170 \\
S6 & 8.936 & 13.404 \\
S7 & 70 & 6.702 & 15.638 \\
S8 & 80 & 2.468 & 17.872 \\
S9 & 90 & 0 & 20.106 \\
S10 & 100 & & 22.340 \\
\hline
\end{tabular}

\subsection{Curing Specimens}

The specimens were left undisturbed in a relatively humid environment for about 24 hours after ramming had been completed. At the end of this period, the specimens were removed from the moulds and submerged completely in clean fresh water and kept there until taken out just prior to testing. The water in which they were completely submerged were renewed every 7 days (for curing periods of 28 days) and maintained at ambient temperature. Care was taken that samples were not allowed to get dry until curing test was conducted (Fig.3)

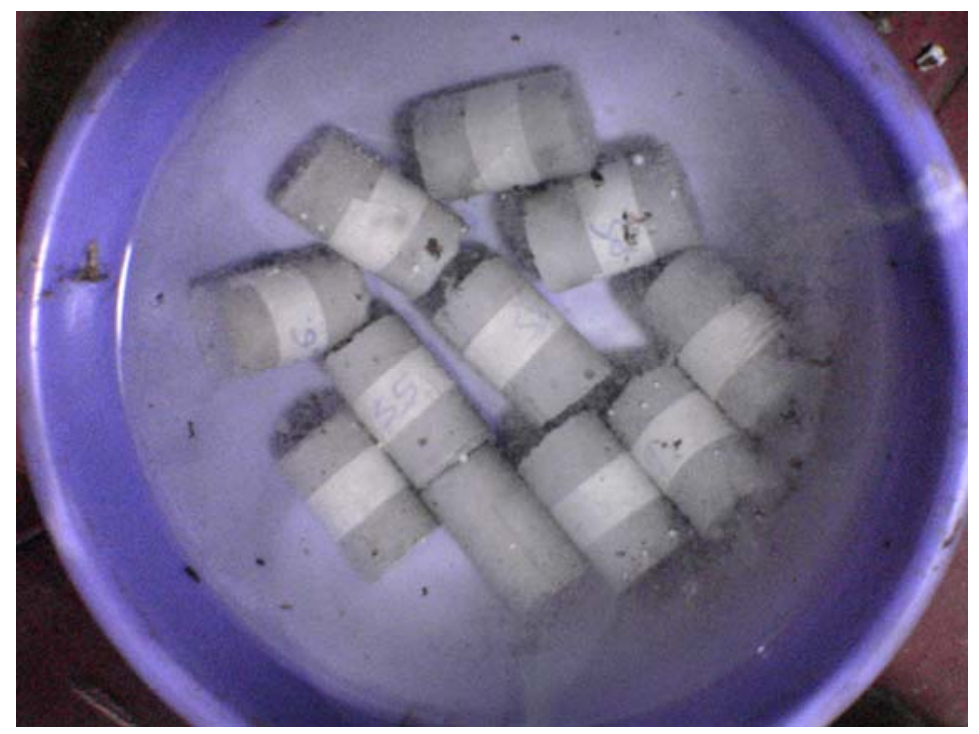

Fig.3: Cured Brick Samples

\subsection{Compressive Tests}


The specimens were tested for compressive strength immediately after removal from the curing chamber while they were still wet. Surface water and grit were wiped off the samples and all projected fins were removed gently with the aid of a hand file. Three samples per each mix proportion were tested and the average was found. The load was then steadily and uniformly applied starting from zero until the test piece just fractures(Fig.4). The fracture load was noted and recorded.

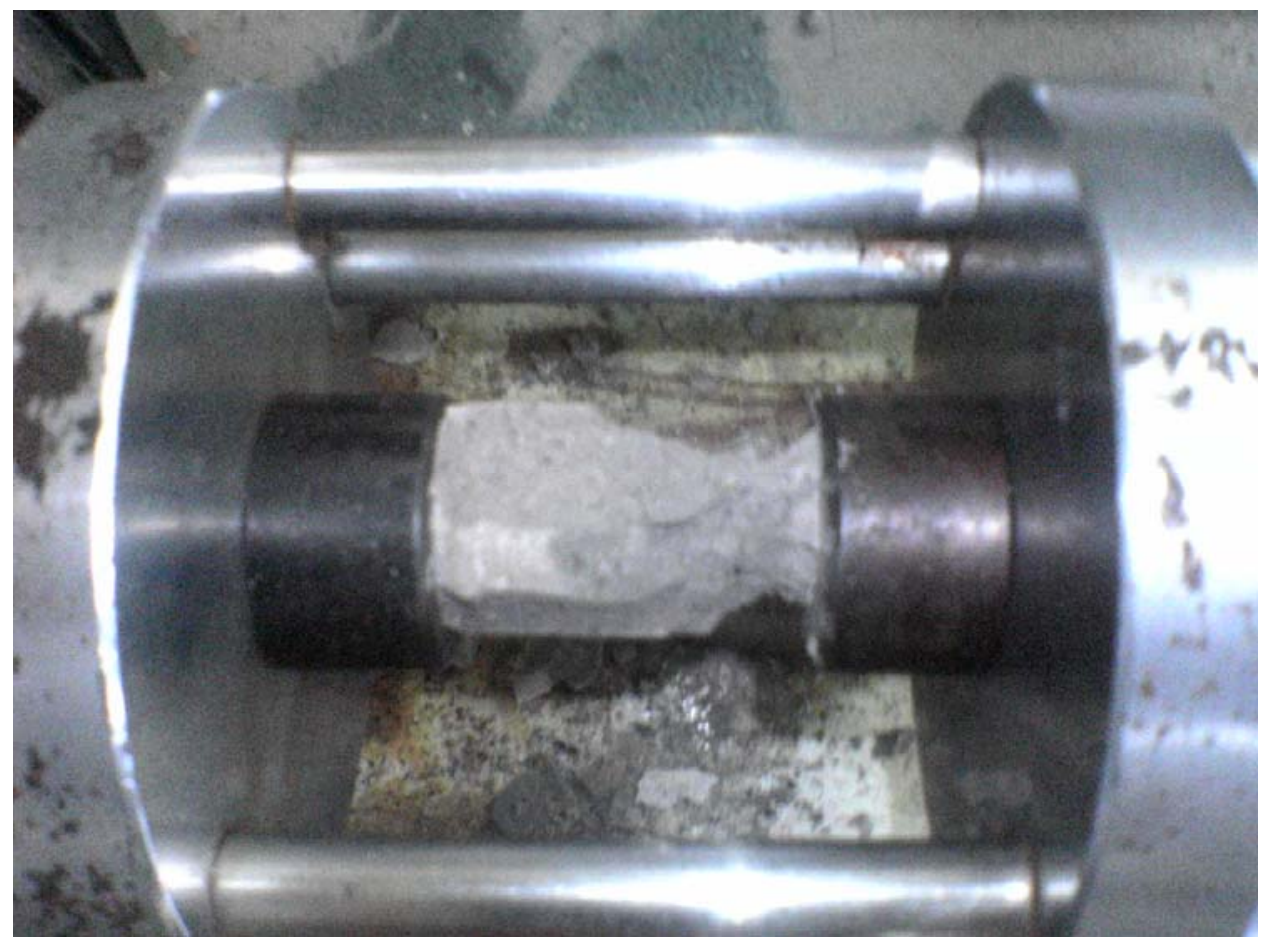

Fig.4: Brick fracturing during compression

The compressive strengths for the specimens were calculated from the crushing load and the cross sectional area over which the load was applied by using the equation:

Compressive strength $=\mathrm{P} / \mathrm{A}$

Where $\mathrm{P}=$ crushing load, $\mathrm{A}=$ cross sectional area of the specimen. Comparison of result was made with value of bricks with no ash additives which is $23.5 \mathrm{~N} / \mathrm{mm}^{2}$ [8]. Requirements for general use concrete is about $21 \mathrm{~N} / \mathrm{mm}^{2}$ [8].

\subsection{Leaching Test}

Leaching test was carried out on the sample with maximum strength i.e. sample with $20 \%$ ash substituted for cement. Leaching test was performed at room temperatures. The sample was first finely ground and separated into particle sizes of $2.8 \mathrm{~mm}, 1.4 \mathrm{~mm}, 1.1 \mathrm{~mm}, 300 \mu \mathrm{m}$ and $250 \mu \mathrm{m}$ using the BS 410 full tolerance test sieve. Concentrated nitric acid was used for leaching. 3g each of the ground samples were then measured and poured into five separate beakers. The acid solution was then poured into the beakers and agitated for an hour. Afterwards the mixtures were filtered through a filter paper. The filtrate was collected and 
analyzed using atomic absorption spectrometry (AAS). The results obtained from the analysis are presented in Table3. Immobilization coefficient of leaching was calculated using the equation:

Immobilization coefficient $=$ (leached value of pure ash - leached value of concrete)/leached value of pure ash) [9].

\section{RESULTS AND DISCUSSION}

\subsection{Results}

The compressive strengths of the various sand/cement/ash and water admixtures are presented in Figures 5 and 6. Figure 5 shows the case where ash is substituted for cement while Figure 6 shows the situation where ash is substituted for sand samples. It could be seen in Figure 5 that compressive strength of bricks substituted with ash up to $20 \%$ in place of cement and cured for 28days were stronger than bricks without any ash content. In Figure 6, bricks with ash substituted up to $40 \%$ in place of sand and cured for 28days had compression strengths higher than bricks without ash content. The two plots also showed that curing at 28 days gave best compressive strengths. The plots also showed that all the samples cured for less than 28 days had compressive strengths less than bricks with no ash content cured for 28days.

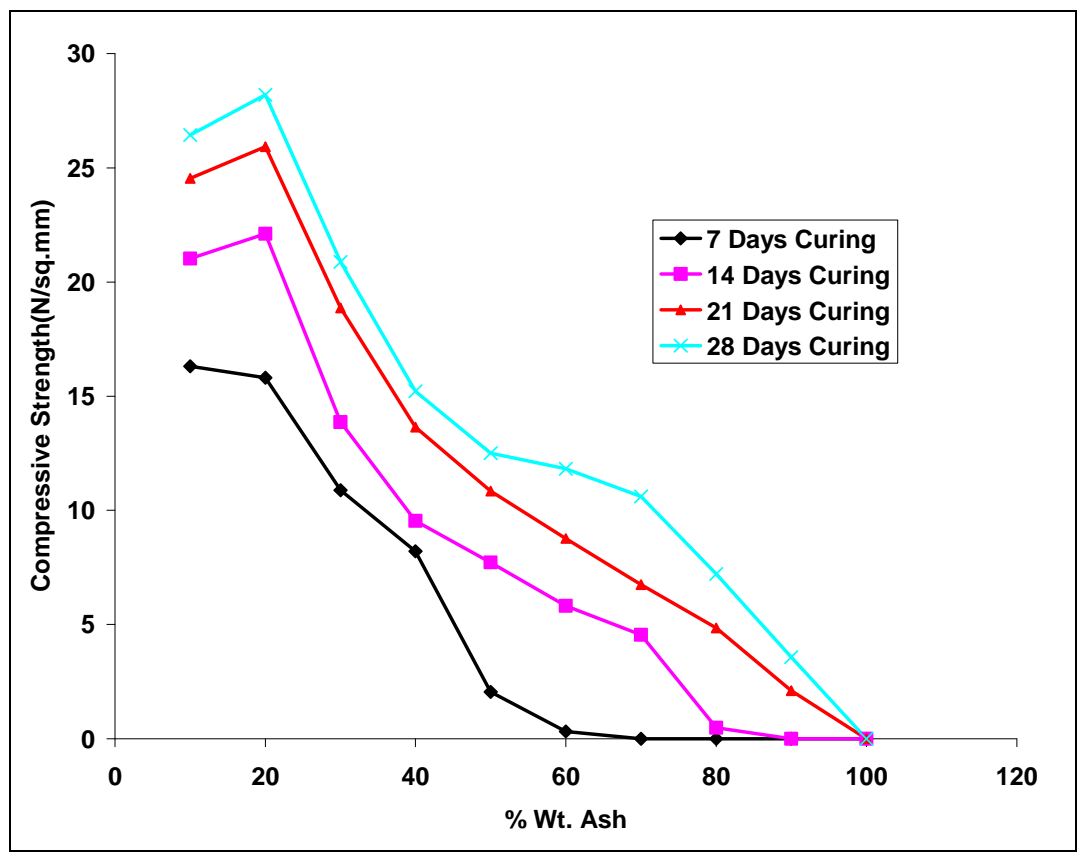

Fig.5: Compressive Strength versus \%wt ash substituted for cement; with sand and water content kept constant. 


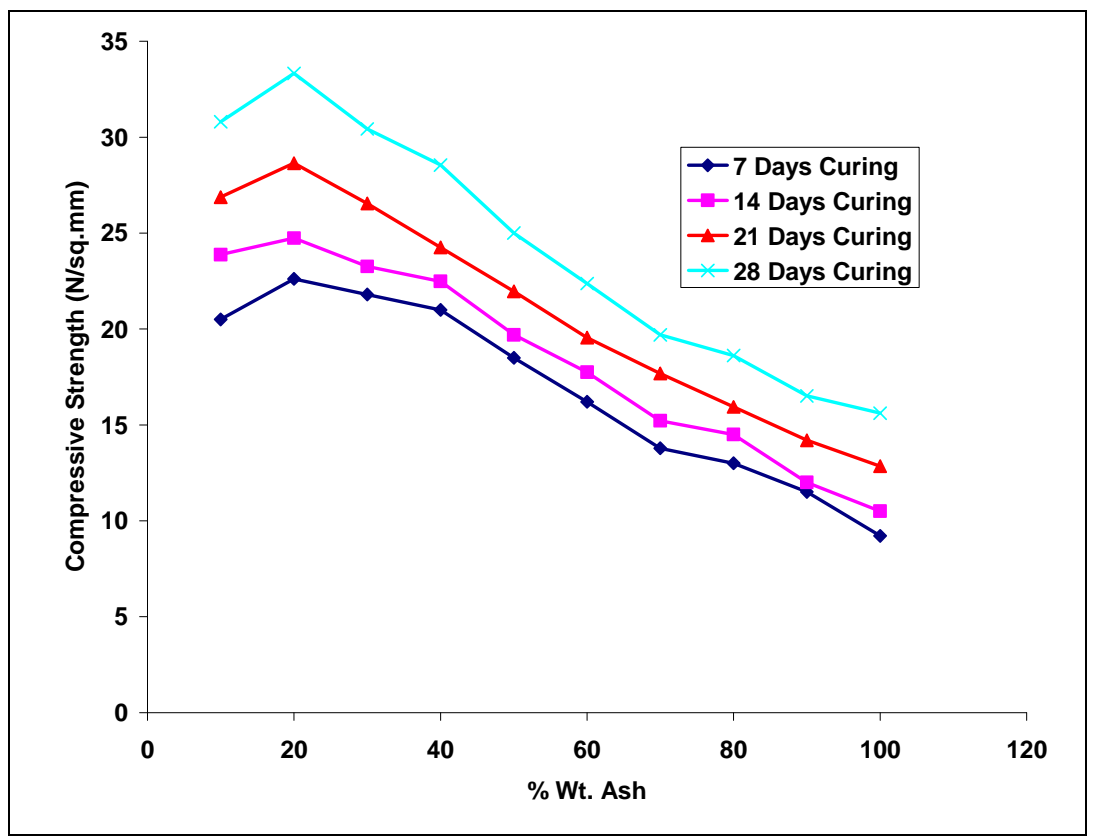

Fig.6: compressive strength versus \%wt ash substituted for sand; with cement and water content kept constant.

Figure 7 shows particle size effect on leaching of heavy metals present in the ash in the bricks. The result showed that leaching increased with decreasing particle size of bricks.

Table 3 presents the immobilization coefficient for the leaching reactions. It showed immobilization coefficient was highest for smallest particle size and lowest for the biggest particle size.

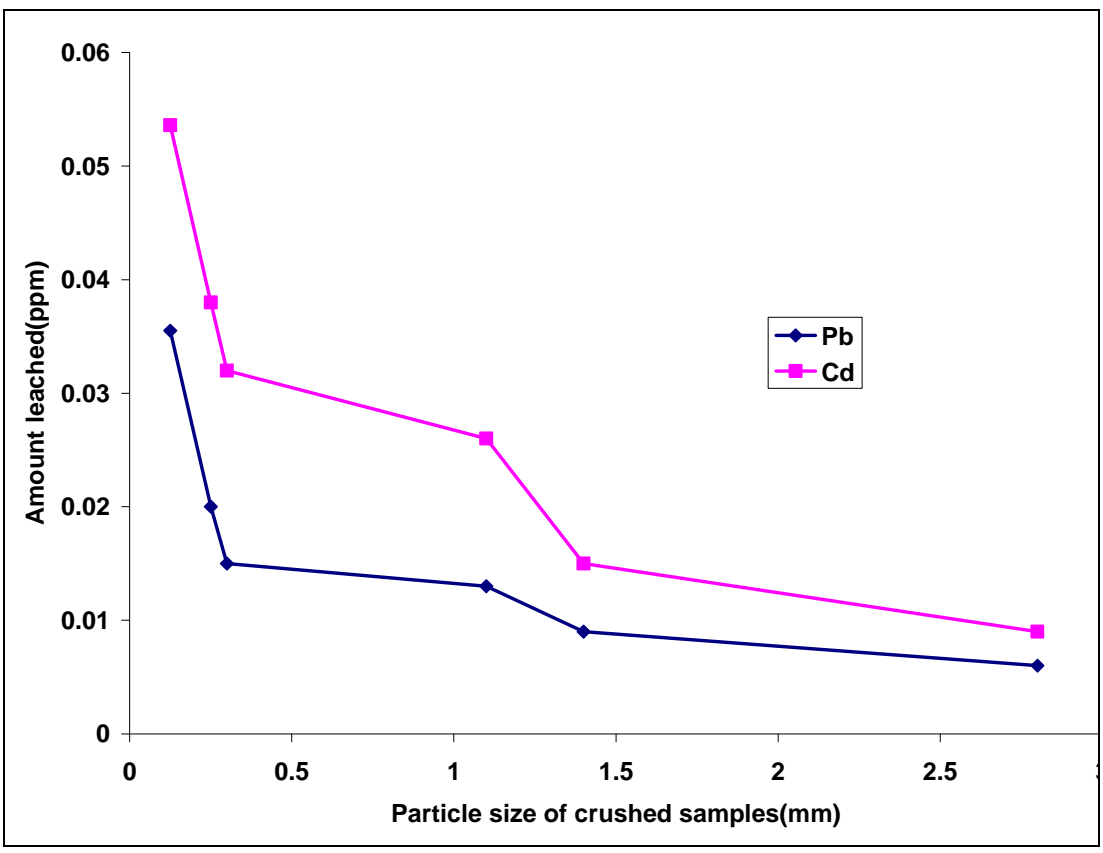

Fig.7: Effect of crushed concrete particle size on Concentrated Nitric acid leaching of heavy metals present in the ash incorporated in the bricks. 
Table 3: Immobilization coefficient for leaching operations.

\begin{tabular}{|l|c|c|}
\hline $\begin{array}{l}\text { Specimen } \\
\text { identification }\end{array}$ & $\begin{array}{c}\text { Immobilization coefficient } \\
(\mathrm{Pb})(\%)\end{array}$ & $\begin{array}{l}\text { Immobilization coefficient } \\
(\mathrm{Cd})(\%)\end{array}$ \\
\hline $2.8 \mathrm{~mm}$ & 43.7 & 44.0 \\
\hline $1.4 \mathrm{~mm}$ & 57.7 & 65.2 \\
\hline $1.1 \mathrm{~mm}$ & 63.4 & 72 \\
\hline $300 \mu \mathrm{m}$ & 74.6 & 83.2 \\
\hline $250 \mu \mathrm{m}$ & 83.1 & 62.7 \\
\hline
\end{tabular}

\subsection{Discussion}

Replacement of sand by incinerator ash(Fig.5) up to $40 \%$ exhibited a higher compressive strength than the control mix ( $0 \%$ incinerator ash) after 28 days of curing. The maximum compressive strength of $33.33 \mathrm{~N} / \mathrm{mm}^{2}$ was achieved using $20 \%$ incinerator ash after 28 days of curing.

Specimens prepared using 20\% incinerator ash replacement for cement (Fig.6)yielded a higher compressive strength than the control mix after 7 and 28 days of curing. The maximum compressive strength of $28.2 \mathrm{~N} / \mathrm{mm}^{2}$ was achieved after 28 days curing period.

From Fig.7, the results for leaching show that as the particle size of the crushed brick increases, the leachability of heavy metals decreases. This is expected because the finer the communition, the easier it is for the leachant to reach the species in the interlocking bricks. Water when used as leaching agent, showed no detectable leaching of heavy metals at the temperature, leaching time and particle sizes used.

Also, there was substantial amount of heavy metal ( $\mathrm{Pb}$ and $\mathrm{Cd}$ ) leaching for all replacement of cement by ash in interlocking bricks. The immobilization coefficients for the concrete crushed to various particle sizes showed the obvious pattern reflected in the leaching operation.The smaller sized particles leached better and had higher immobilization values.

\section{CONCLUSION}

This work has shown that the fly-ash generated from the Nigerian petroleum waste incineration plants can be suitably substituted for cement up to $20 \%$ replacement in use as interlocking bricks constituent. At this level of replacement, the bricks will achieve a compressive strength of $15.81 \mathrm{~N} / \mathrm{mm}^{2}, 22.11 \mathrm{~N} / \mathrm{mm}^{2}$ and $28.20 \mathrm{~N} / \mathrm{mm}^{2}$ for 3 days, 7 days and 28 days curing periods respectively which fall under the acceptable values for compressive strengths of interlocking bricks as stipulated by BSI 4550:Part 5:1972. 
The results for leaching show that as the particle sizes of the crushed concrete increases, the leachability of heavy metals decreases being locked in the mass of brick.

\section{REFERENCES}

[1] Murthy, N. N, (1996) Engineering materials. Dhanpat Publications, New Delhi. India

[2] Wikepedia(2007) 'Concrete’ en.wikipedia.org/wiki/Concrete(Assessed 2010)

[3] American concrete Institute(1963) ‘Admixtures for concrete’Journal of ACI Proceedings, 60(11), 1512.

[4] Hope,B and Brian.B(1981) “Autoclaved Concrete Containing Fly Ash”, cement and Concrete Research, 11( 2), 227.

[5] Valore, R.C.Jr.(2007) "Laboratory Evaluation of Fly Ash and Other Pozzolans for Use in Concrete’www.en.wikipedia.org/wiki/flyash.2007 Fly ash.

[6] Lovewell, C.E. and Washa, G.W.(1958) 'Proportioning Concrete Mixes Using Fly Ash' Journal of The American Concrete Institute, 54(12).

[7] U.S. Department of Interior, Bureau of Reclamation, Fly Ash Increase Resistance to Sulfate Attack, Research Report No. 23, 1970, p.5.

[8] IEA-COAL(Assessed 2010) 'Utilisation of ashes, slags and residues’http://ieacoal.org.uk/catalogues/coalonline/.../html/5945_237.html

[9] Esaki M., Kawakami I., Sumitomo M.(1995) 'Immobilization of fly ash with cement solidification and chemical treatment' Proceedings of the 6th Annual Conference of Japan Society of Waste Management Experts, , pp. 432 - 434. 